ISSN 1518-3483

Licenciado sob uma Licença Creative Commons

\title{
Escolarização da infância em cidades de colonização recente de Mato Grosso
}

\author{
Escolarización de la infancia en ciudades de colonización \\ reciente de Mato Grosso
}

\section{Elizabeth Figueiredo de Sá, Clailton Lira Perin, Katia Maria Kunntz Beck ${ }^{*}$}

Universidade Federal de Mato Grosso, Cuiabá, MT, Brasil

\section{Resumo}

O presente artigo se insere nas discussões sobre os processos históricos de fundação e constituição da educação em cidades de Mato Grosso, colonizadas no século XX, de modo a conhecer, analisar e contribuir para com o entendimento da seguinte problemática: Como fora tratada a escolarização da infância durante o "estímulo" à ocupação territorial do estado entre os anos de 1960 a 1980? A pesquisa se desenvolveu na perspectiva da Nova História Cultural. A delimitação do estudo justifica-se em razão do processo de colonização por empresas privadas terem iniciado seus trabalhos a partir da década de 1960, ocasionando acentuado processo migratório para o território mato-grossense,

\footnotetext{
EFS: Doutora em Educação, e-mail: elizabethfsa1@gmail.com

CLP: Mestre em Educação, e-mail: spapensador@hotmail.com

KMKB: Mestre em Educação, e-mail: katiamkb@gmail.com
} 
principalmente para as regiões que receberam um forte estímulo do estado para tornar essas localidades produtivas economicamente. Para tal, as cidades de Tangará da Serra e Alta Floresta serviram de lócus para tal investigação, por terem sido criadas e administradas por colonizadoras privadas que atraíram a migração de colonos da região Sul e Sudeste do Brasil para trabalhar com o cultivo de terras no estado de Mato Grosso. As empresas colonizadoras buscavam concretizar seus interesses, e, para tal, assumiam a responsabilidade de todo o empreendimento como as obras de infraestrutura, medição e demarcação das terras, abertura de estradas vicinais, implantação de núcleos urbanos, instalações de serviço de saúde, educação, ações sociais, entre outros. A pesquisa possibilitou perceber que as iniciativas voltadas para a escolarização da infância, embora contassem com o compromisso do estado e das colonizadoras, foram resultantes de iniciativas dos próprios migrantes.

Palavras-chave: Colonização recente. Processo migratório. Escolarização da infância. Educação mato-grossense.

\section{Resumen}

El presente artículo se insiere en las discusiones sobre los procesos históricos en la fundación y constitución de la educación en ciudades de Mato Grosso, colonizadas en el siglo XX, para conocer, analizar y contribuir con el entendimiento de la siguiente problemática: ¿Cómo fue tratada la escolarización de la infancia durante el "estímulo" a la ocupación territorial del estado entre los años de 1960 a 1980? La investigación se desarrolló en la perspectiva de la Nueva Historia Cultural. La delimitación del estudio se justifica en razón del proceso de colonización por empresas privadas que iniciaron sus trabajos a partir de la década de 1960, ocasionado un acentuado procesos migratorio para el territorio mato-grossense, principalmente para las regiones que recibieron un fuerte estímulo del estado para tornar esas localidades en lugares económicamente productivos. Para lo cual, las ciudades de Tangará da Serra y Alta Floresta sirvieron de lugar para tal investigación, por haber sido creadas y administradas por colonizadoras privadas que atraían la migración de colones de la región sur y sureste de Brasil para trabajar con el cultivo de tierras en el estado de Mato Grosso. Las empresas colonizadoras buscaban concretar sus intereses, y, para tal asumían la responsabilidad de todo el emprendimiento como las obras de infraestructura, medición 
y demarcación de las tierras, abertura de las carreteras vecinales, implantación de núcleos urbanos, instalaciones de servicio de salúd, educación, acciones sociales, entre otros. La investigación posibilitó percibir que las iniciativas volcadas para la escolarización de la infancia, a pesar de que se contaba con el compromiso del estado y de las colonizadoras, fueron resultados de iniciativas de los propios migrantes.

Palabras clave: Colonización reciente- proceso migratorio- escolarización de la infanciaeducación mato-grossense.

\section{Introdução}

Desde as últimas décadas do século XIX e as primeiras do século XX percebe-se iniciativas do Estado brasileiro em definir e nacionalizar as suas fronteiras. No entanto, é a partir do Governo Vargas, com o chamado projeto Marcha para Oeste, Vargas, que tal projeto ganhou força por meio da ocupação do "vazios" demográficos. A respeito, Paes (2011, p. 184) afirma:

A "Marcha para o Oeste" teve, por escopo, a fundação de cerca de quarenta e três (43) vilas e cidades, a construção de dezenove (19) campos de pouso, o contato com mais de 5 mil índios e distâncias percorridas num aproximado de 1,5 mil quilômetros (picadas abertas e rios) [...]. $\mathrm{Na}$ iniciativa proposta para a região, os colonos preferidos eram os sulistas, por serem de origem europeia e terem sede de progresso. Esses colonos recebiam provisoriamente as terras e, depois de três anos, o título definitivo da propriedade.

A partir de 1964, dando continuidade à política de integração da Amazônia à economia nacional e, com o intuito de atenuar a crise na economia rural que se acentuava principalmente nas regiões Sul, Sudeste e Nordeste, o governo voltou-se para a ampliação de políticas públicas que 
pudessem concretizar o processo de reocupação ${ }^{1}$ territorial da Amazônia. Nesse sentido, foram criados órgãos governamentais voltados para a coordenação, instalação e implantação de projetos que visavam a expansão da região, através da aquisição de terras e, com isto, promoveu o deslocamento de um grande número de trabalhadores migrantes (ROHDEN, 2012).

Seduzidos pelas promessas de terras férteis e de moradias em locais com infraestrutura para a família, os migrantes e suas famílias, principalmente do estado do Paraná, ajuntaram seus pertences e viajaram durante dias na boleia de caminhões em busca do que seria o novo "Eldorado", a "Nova Canaã", terra de sonhos, esperança de um futuro melhor. Expectativas, receios e cansaço os acompanharam durante o percurso que os levariam ao inesperado.

Ao fim do trajeto a desilusão. A realidade não era o esperado ou o prometido. Era um nada no meio do nada. Várias questões passaram por suas mentes: voltar ou insistir? Voltarmos para onde se desfizemos do pouco que tínhamos? Insistir em que, se tudo está por fazer? Dúvidas e incertezas: o que fazer? Encurralados, os migrantes se viram sem opções, a não ser instalar suas famílias nos locais adquiridos e torná-los habitáveis.

Este artigo se insere nas pesquisas que compõem o projeto "Das escolas de madeira e pau-a-pique": os processos históricos da fundação e constituição da Educação em cidades de Mato Grosso colonizadas no século XX" que investiga os processos históricos de fundação e constituição da educação em cidades de Mato Grosso, colonizadas no século XX, de modo a conhecer, analisar e contribuir para com o entendimento da seguinte problemática: Como fora tratada a escolarização da infância durante o "estímulo" à ocupação territorial do estado entre os anos de 1960 a 1980 ?

1 O termo (re)ocupação é usado para dizer que nessas regiões (Centro-Oeste e Amazônia) já eram ocupadas/ habitadas por várias etnias indígenas, posseiros, ribeirinhos, entre outros, e que não eram "vazios demográficos" como era colocado pelo governo militar. Sobre esse assunto, ver Barrozo (2008), Joanoni Neto (2007), Guimarães Neto (2002). 
A delimitação do estudo justifica-se em razão do processo de colonização por empresas privadas ter iniciado seus trabalhos a partir da década de 1960, ocasionando acentuado processo migratório para o território mato-grossense, principalmente para as regiões que receberam um forte estímulo do estado para tornar essas localidades produtivas economicamente. Para isto, as cidades de Tangará da Serra (localizada ao Sudoeste do estado) e a cidade de Alta Floresta (situada na porção Norte) serviram de lócus para tal investigação. Tais cidades possuem em comum as características do processo de colonização, que foram realizadas por colonizadoras privadas e direcionadas, principalmente, para atrair os colonos da região Sul e Sudeste do Brasil a migrar para trabalhar com o cultivo de terras no estado de Mato Grosso.

Cabe ressaltar que as empresas colonizadoras buscavam concretizar seus interesses, e, para tal, assumiam a responsabilidade de todo o empreendimento como as obras de infraestrutura, medição e demarcação das terras, abertura de estradas vicinais, implantação de núcleos urbanos, instalações de serviço de saúde, educação, ações sociais, entre outros. Entretanto, apesar de características comuns entre as cidades investigadas no processo de colonização, é relevante salientar que, cada uma possui uma história singular, e, que, portanto, necessitarão de um trato peculiar no que se refere ao estudo e análise da história da Educação. Para isso, buscaremos em Certeau $(2004,1994)$ enfatizar a cultura produzida pelo "homem comum" no movimento do pensar sobre a invenção e reinvenção do cotidiano dos sujeitos envolvidos nesta pesquisa de cunho historiográfico.

\section{A formação do povoado e da escola de Tangará da Serra}

Escrever sobre o movimento de migração durante o período de colonização de Tangará da Serra significou entrelaçar a prática interpretativa à prática social, ou seja, possibilitou a historicidade do percurso entre os lugares próprios até os espaços transformados, evidenciando o que se 
denomina de artes de fazer, que "[...] constituem as mil práticas pelas quais usuários se reapropriam do espaço organizado pelas técnicas da produção sócio cultural" (CERTEAU, 1994, p. 41). Espaço, este sonhado pelos migrantes oriundos de diferentes estados do Brasil, que deixaram para trás amigos, familiares, suas moradas, suas vivências; mas trouxeram consigo lembranças, histórias, amor, cultura, as crenças, a esperança de uma vida melhor, a experiência de vida no campo e construíram um novo espaço de formas de fazer. Os primeiros migrantes que andaram pela estrada sem rumo, sem flor chegaram a partir de 1959, oriundos dos estados de São Paulo, Minas Gerais, Paraná e da região Nordeste do Brasil e, logo foram se organizando com muita dificuldade no novo espaço. Formaram um povoado no território que, àquela época, pertencia ao município de Barra do Bugres (OLIVEIRA, 2004). Essa movimentação deu nascimento ao loteamento das glebas Santa Fé, Esmeralda e Juntinho, que, anos depois, graças ao grande fluxo migratório proveniente de representações positivas divulgadas por meio da imprensa pela colonizadora e pelo governo estadual e federal, ganhou a toponímia de "Cidade de Tangará da Serra", ainda adstrita a Barra do Bugres

Os migrantes, foram incentivados pelas propagandas divulgadas pela colonizadora privada Sociedade Comercial Imobiliária de Tupã para a Agricultura Ltda (SITA) e pelo governo de Mato Grosso que destacavam a fertilidade do solo e a possibilidade de sua aquisição a preços acessíveis para pequenos produtores rurais, bem como a possibilidade de estímulos e favores fiscais na aquisição de terras, pois, "objetivavam atrair pequenos proprietários do Sul do país para produzirem alimentos e outros produtos para o mercado interno e para a exportação" (ABREU, 2001, p. 71). No decorrer dessa movimentação, os próprios migrantes chamavam parentes e amigos, que ficaram no local de origem, para vir povoar os novos espaços do imenso sertão mato-grossense, e, à medida que os caminhões com as mudanças chegavam, trazendo várias famílias e seus parcos pertences, eles iam se acomodando e se organizando como era possível, até conseguir seu próprio lugar. 
A expectativa pela posse da terra e pela possibilidade de um futuro promissor, através da reocupação desse espaço de terra fértil, estimulou a superação das dificuldades da viagem e do que encontraram ao chegar.

No projeto elaborado pela colonizadora estava previsto onde seriam erguidas as edificações: mercado, farmácia, hospital, rodoviária, praças, grupo escolar, cinema, estádio de futebol, posto de saúde, delegacia, aeroporto e outros. Os migrantes, ao visualizarem o planejamento para as futuras instalações de Tangará da Serra, sentiram-se motivados e seguros pelo fato de seus filhos terem a possibilidade de um futuro mais próspero, tendo como pressuposto a educação que receberiam nas instituições escolares, previstas na planta original da futura cidade.

Em vários depoimentos que retratam o período de colonização, os migrantes descrevem o misto entre esperança, luta e conquistas. Foram muitos os caminhões pau-de-araras transportando mudanças de várias famílias para Tangará da Serra. Iludidas ou não, estas famílias vieram individualmente ou em grupos de vizinhos, de amigos, de parentes ou de patrões e empregados, para habitar e construir suas vidas neste espaço de Mato Grosso (OLIVEIRA, 2009, p. 68). Caminhões que demoraram oito, quinze e até vinte dias de viagem até o destino, os quais chegaram abrindo estrada com o para-choque no meio de cerrado, carregando famílias inteiras, "[...] pessoas que tinham os corações divididos entre a saudade do lugar que deixavam e a vontade de vencer e melhorar seu futuro no lugar em que agora iriam estabelecer" (OLIVEIRA, 2009, p. 68). Algumas famílias chegaram com caminhão velho até Nova Olímpia, e de lá subiram a Serra a pé, o que chegava a durar três dias.

Porém, mesmo com a chegada das primeiras famílias à localidade de Tangará da Serra (1959) e, com o número crescente de crianças que chegavam a cada dia, a empresa colonizadora não executou o que havia planejado, inclusive referente à construção de instituições escolares, mobilizando-os à luta pela criação de uma escola no povoado, em 1964. Conforme Oliveira (2009), desse movimento surgiu a primeira escola na localidade urbana, porém reconhecida oficialmente como rural, pois como 
Tangará da Serra era localidade 2 de Barra do Bugres, naquela época. Por isso a primeira escola era considerada rural, mesmo estando localizada em espaço urbano.

Destaca-se o fato de que as famílias migrantes deram sentido ao ato de fazer e refazer o cotidiano a partir das suas necessidades, desse modo, se uniram para construir a escola. Assim, entendemos que as famílias, convencidas da necessidade de escola para seus filhos, se mobilizaram, conquistaram e edificaram a primeira escola na localidade de Tangará da Serra ${ }^{3}$.

A instituição escolar foi oficialmente denominada Escola Rural Mista de Instrução Primária de Tangará da Serra, criada pelo decreto ${ }^{\circ}$ 813, de 4 de setembro de 1964, publicado em Diário Oficial do Estado de Mato Grosso, na mesma data. No registro de matrículas consta que foram realizadas 107 matrículas no dia 31 de março de 1964 e que, após esta data, foram realizadas mais 35 matrículas que chamaram de progressivas, em virtude de terem sido efetivadas após o início das aulas até o mês de setembro do ano letivo. Conforme chegavam os migrantes, as crianças eram matriculadas, portanto, como demonstra o registro de matrículas, no ano de 1964, foram matriculados 142 alunos distribuídos entre a $1^{\mathrm{a}} \mathrm{a}$ $4^{\mathrm{a}}$ séries.

A escola era mantida pelo governo do estado de Mato Grosso, porém podemos constatar que o primeiro termo de visita à escola foi registrado somente um ano após o início do funcionamento da escola, conforme consta em um termo de visita realizado por um inspetor de ensino, no Livro de matrícula (1964, p. 75):

Aos sete dias do mês de junho de mil novecentos e sessenta e cinco, em visita a escola rural mista do lugar denominado - Tangará da Serra no município de Barra do Bugres onde fui recebido gentilmente pelos professores José David Nodari, Terezinha Sassaki e Aldo

2 O termo localidade (hoje denominada de distrito) era utilizado para informar que o espaço pertencia a um município.

3 Tangará da Serra teve sua emancipação político-administrativa no dia 13 de maio de 1976. 
Sassakie percorrendo as salas de aulas encontrei em ordens as referidas salas contendo cada uma 12 bancos, 1 quadro negro, mesa, etc. Encontrando também em cada sala, mapas do Brasil e do Estado. $\mathrm{Na}$ área pertencente à escola, instalada duas casinhas sanitárias para meninos e meninas, achando-se em construção um poço já com 12 metros de profundidade. A escola que acha-se guarnecida com uma área de mais ou menos 8 metros em volta digo em redor mantêm sempre limpa. Tem também as suas escritas em perfeita ordem a qual fez lavrar o presente termo.

A representação de espaço educacional demonstrada pelo inspetor de ensino evidencia uma preocupação com a existência da escola, seu funcionamento, a ordem, a organização e a limpeza. Portanto, permite-se refletir sobre qual o modelo de escola que atendia às crianças migrantes, "[...] uma escola isolada mal assistida pelos poderes públicos, municipal e estadual, porém uma escola em movimento para a população que migrava para Tangará da Serra" (OLIVEIRA, 2009, p. 93). Percebe-se a importância dada à educação através da existência da escola para o atendimento ao movimento migratório, porém não é possível perceber a preocupação com a qualidade da educação, tampouco com a formação dos professores.

A partir de 1965, um grupo de famílias que estava residindo no espaço rural denominado "Reserva" localizado a, aproximadamente, 10 km do povoado de Tangará da Serra ${ }^{4}$, se reuniu com o objetivo de construir uma escola, mais próxima de suas casas, devido a distância que seus filhos tinham que percorrer até à escola estadual e, por causa do crescente número de crianças que chegavam com a família para morar naquele espaço. Assim, as famílias com o apoio de Antônio Galhardo, proprietário do sítio Santo Antônio na Reserva, se movimentaram para construir a escola (GALHARDO. Depoimento, Tangará da Serra, 26/06/2014 ${ }^{5}$ ). Eles

4 Era assim chamado o espaço que futuramente seria urbano, pois nesse período Tangará da Serra ainda era localidade de Barra do Bugres.

5 GALHARDO, D. C. Depoimento [jun. 2014]. Entrevistadora: K. M. K. Beck. Cuiabá: IE/UFMT 2014. (0: 17 min.). Entrevista concedida ao Grupo de Pesquisa em História da Educação e Memória (GEM). 
vivenciaram o que Certeau (1994) chama de "táticas", ou seja, buscaram maneiras de viver e fazer em comunidade para suprir, de alguma maneira, as necessidades do grupo, visando alcançar o que vieram buscar.

Para "erguer a escola", como os antigos moradores relatam, utilizaram dos materiais de que dispunham na localidade, madeira, retirada do mato, e barro, justamente os mesmos materiais que compunham as casas ou "ranchos" onde habitavam. A aluna da escola daquele período, Ivonete Maria Oliveira, que também estudou nesta instituição, conta o que lembra a esse respeito:

A escola era feita de coqueiro lavrado, eles abria o coqueiro e fazia a escola, coberta de tabuinha, lá fora era um terrenão bruto, não tinha piso, era chão, tinha um poço que a gente tirava água lá... tinha um pouco de sombra... dentro da sala tinha aqueles bancão de pau bruto, que os pais fizeram com a madeira que tiravam do mato, a mesa era de tábua bruta 114 também, um banco cabia quatro aluno, num banco só. A professora organizava as criança que era da quarta série numa mesa, da terceira na outra, a segunda na outra e a primeira... era tudo assim... separado por mesa. Banheiro não tinha, era o mato mesmo, depois de um tempo fizeram um mictório, um buraco no chão com uma casinha. Os pai dos aluno se ajuntaram e tiraram as madeira do mato com o machado, que não tinha muita ferramenta e carregaram nas costa esses pau tudinho, levantaram a escolinha, aí a dona Iracema começo lecionar nessa escolinha e eu era uma das alunas (OLIVEIRA, Depoimento. Várzea Grande, 10/08/20146).

Percebe-se a participação efetiva da comunidade rural na criação da Escola Rural Mista Municipal Santo Antônio, que, a partir do dia 18 de junho de 1965, passou a funcionar, contando com dezoito alunos matriculados. Aos poucos, o número de crianças foi aumentando, chegando ao total de 80 alunos, sendo 40 no período matutino e 40 no período

6 OLIVEIRA, I. M. Depoimento [agost., 2014]. Entrevistadora: Kátia Maria Kunntz Beck. Cuiabá: IE/ UFMT. 2014. (0:39 CAMILO, Severino da Silva. [maio 2014]. Entrevistadora: K. M. K. Beck. Cuiabá: IE/UFMT 2014. 
vespertino. Ensinar a essas crianças representou um desafio para a professora leiga Iracema Casagrande, "apontada" pela comunidade, como ela própria diz, para ser a professora da escola, pois era a única que tinha estudado até a $4^{\mathrm{a}}$ série:

Eu comecei a dar aula sem saber como começava (risos). Porque eu nunca tinha dado aulas, né? Não tinha preparação, o que eu aprendi, o que eu sabia que eu tinha só até a $4^{\mathrm{a}}$ série né? Minha $4^{\mathrm{a}}$ série fiz no ano de 42, o que eu aprendi, o que eu sabia na escola, o que eu aprendi desde a primeira série, eu comecei a ensinar para minhas crianças (CASAGRANDE, I. apud Núcleo de Documentação de História Escrita e Oral (NUDHEO), 20067).

A dificuldade da professora não era apenas de cunho pedagógico, por não ter a formação adequada, mas estava associada à escassez de materiais pedagógicos e de recursos humanos na escola. Foi por meio de suas reivindicações que a escola foi mobiliada, embora ainda de forma insuficiente. Assim, mesmo com toda dificuldade e com a formação limitada, a professora Iracema tornou-se uma das lideranças na comunidade, exercendo uma forte influência na formação da infância local, pois além do ensino, dava-lhes a formação religiosa.

A escola se constituía, para os alunos, em espaço para estudar e aprender, para "ser alguém" mais importante do que apenas um trabalhador da roça, mas, sobretudo, como um espaço preferido comparado ao espaço de trabalho, pois, mesmo durante um pequeno período, poderiam também, brincar, correr, jogar bola (ou laranja) com os amigos, enfim, a escola era considerada um espaço divertido e alegre, apesar do esforço e concentração necessários para se apreender.

7 CASAGRANDE, Iracema da Silva Machado. Depoimento [fevereiro 2006]. Entrevistador: Carlos Edinei de Oliveira. Tangará da Serra: UNEMAT. 2006. (2:48:17 min.). Entrevista concedida ao Núcleo de Documentação de História Escrita e Oral (NUDHEO). 


\section{A importância da escola no processo de colonização de Alta Floresta-MT}

Diferentemente de Tangará da Serra, o projeto de Alta Floresta, desenvolvido pela colonizadora Integração Desenvolvimento e Colonização (INDECO), criada por Ariosto da Riva em 1973, contou com mais organização do espaço e com projeto de escolarização da infância mais focado em fixar o migrante e sua família na gleba.

Com o projeto elaborado ${ }^{8}$, Ariosto participou da concorrência pública aberta pelo Edital n ${ }^{\circ}$ 03/73, de 25 de julho de 1973, da Companhia de Desenvolvimento do Estado do Mato Grosso (CODEMAT), que colocou à venda ${ }^{9}$ (JATENE, 1983). Após ganhar, começou os trabalhos para a implantação do projeto de colonização de Alta Floresta, iniciando com a construção da rodovia J1 que ligava a área de colonização com a rodovia Cuiabá-Santarém (BR-163), abrindo acesso à capital do estado, pois, até então, o acesso era difícil até mesmo de avião.

Com a conclusão dessa rodovia investiu na parte estrutural, isto é, na organização e construção de uma infraestrutura para a implantação do núcleo urbano. As terras foram organizadas nas glebas Alta Floresta e Paranaíta e, posteriormente, a gleba Apiacás. Para cada gleba era previsto um núcleo urbano, com infraestrutura física, social e econômica, e também núcleos de apoio nos principais cruzamentos do sistema viário, que assegurava a cada lote o acesso, não só aos núcleos urbanos, mas também com a rodovia principal J-1 (JATENE, 1983). A demarcação dos lotes foi feita privilegiando a exploração agroflorestal ou agropecuária de grande

8 O artigo 21 do Decreto no 59.428, de 27 de outubro de 1966, regulamentou as diretrizes dos projetos de colonização privada devendo constar: I - caracterização sumária dos aspectos físicos da área, incluindo: Denominação e localização; Topografia, superfície e limites; Vias de acesso e comunicações; Índices climáticos; cobertura vegetal; Solos; Hidrografia; II - esquema da organização proposta para a área incluindo: [...] c) indicação das obras de infraestrutura e dos serviços essenciais a serem instalados [...] (BRASIL, 1966).

9 Dados da Companhia de Desenvolvimento do Estado do Mato Grosso (CODEMAT), cf. Jatene (1983). 
porte, isto é, privilegiando os grandes latifundiários, ficando $30 \%$ da área para o pequeno e médio agricultor. Após a demarcação da área, por meio dos trabalhos de topografia, derrubadas, abertura de estradas, teve início a organização de setores, residências, pontes, bueiros, barracos, alojamento etc. e, aos poucos, a mata virgem foi dando lugar a cidade e a uma colonização [...]" (NUNES, apud, Folha da Floresta 1989, p. 09).

Em maio de 1976 chegaram os primeiros colonos em Alta Floresta. De acordo com Ariosto "[...] pouca gente entrou em 1976, por que nós ainda não tínhamos feito às estradas vicinais" e acrescenta "a gente não podia trazer o colono sem que ele tivesse estradas" (RIVA, apud SCHAEFER, 1985, p. 74). Quando parte da infraestrutura ficou pronta, teve início outra etapa do projeto: a seleção dos $\operatorname{colonos}^{10}$, sendo privilegiados os "[...] agricultores do sul do país, com mais experiência no trato com a lavoura e com recursos financeiros suficientes para comprarem as terras e lotes oferecidos pelas empresas" (SCHAEFER, 1985, p. 50).

Muitos migrantes venderam suas pequenas propriedades no Sul e Sudeste do país e aplicaram no norte de Mato Grosso, acreditando nas propagandas que lhes haviam sido feitas: "a terra sem geada", "a terra prometida que corre leite e mel", existência de uma infraestrutura, como hospital, escolas etc. A INDECO fazia questão de ressaltar em suas propagandas que o seu projeto tinha a aprovação da Superintendência do Desenvolvimento da Amazônia (SUDAM) e do Instituto Nacional de Colonização e Reforma Agrária (INCRA), o que dava legitimidade à aquisição da terra, ressaltada com o slogan: "Terra fértil; Documentação sadia e Acesso permanente".

Pode-se afirmar que as propagandas ocuparam papel fundamental na ocupação de Alta Floresta, uma vez que elas tinham como objetivo mexer com o imaginário das pessoas, fazer com que elas, ao vê-las, ou ouvi-las, viajassem em sua imaginação, almejando um novo lugar, criando, assim, uma "[...] representação, segundo a qual o texto existe em si,

10 Para a ocupação das parcelas dos núcleos de colonização serão recrutados, dentro ou fora do território nacional, indivíduos ou famílias de comprovada vocação agrícola (BRASIL, 1966). 
separado de toda materialidade, é preciso lembrar que não há texto fora do suporte que lhe permite ser lido (ou ouvido) e que não há compreensão de um escrito qualquer que seja, que não dependa das formas pelas quais atinge o leitor" (CHARTIER, 1991, p. 182).

As "longínquas terras férteis da Amazônia eram trazidas para bem perto do imaginário social do pequeno produtor, cabendo, portanto, como em um passe de mágica, ocupá-las [...]" (GUIMARÃES NETO, 2002, p. 25). Nesse contexto, a nova terra era a representação de um mundo fantasioso que estava ao alcance desse produtor, dependendo apenas da decisão dele em migrar ou não em busca dela. Deste modo, a propaganda da colonizadora e o carisma de Ariosto, aliados ao momento que se encontrava a região Sul, principalmente do estado do Paraná, fizeram de Alta Floresta um lugar no qual o pequeno agricultor depositou a esperança em ter uma vida melhor, onde poderia obter terra e criar os seus filhos.

Nesse contexto a escola, que já era utilizada como instrumento de propaganda para atrair os colonos, passou a ter um papel fundamental de formação da infância e sua fixação, bem como de sua família, em sua propriedade agrícola. Por causa disso, a construção de escolas tanto na área rural quanto na urbana tornou-se prioridade para a colonizadora. Exemplo disso é a criação do Instituto de Educação Vitória Furlani da Riva, para gerir a questão da educação no interior do projeto de colonização até que o Estado passasse a assumir tal responsabilidade.

No cenário "urbano", a Escola Vitória Furlani da Riva foi instalada inicialmente no barracão na sede da colonizadora. Contava com professoras que atuavam nas duas classes existentes, sob a direção do professor Benjamim de Pádua, que na ocasião estava incumbido de organizar o sistema educacional de Alta Floresta. Em apenas um ano de funcionamento, outras pessoas vieram a compor o quadro de pessoal da escola, além dos professores, como o diretor escolar, vice-diretor, coordenação pedagógica, supervisão escolar, secretaria, auxiliar administrativo, merendeiras e serviços gerais ou contínuos.

O colonizador acompanhava bem de perto as atividades da Escola, garantindo que fosse conhecido e lembrado. Sua presença era 
constante nas solenidades escolares, tornando-o referência para os colonos e seus filhos.

Aos arredores, conforme os lotes/sítios iam sendo abertos e ocupados pelas famílias de colonos, a comunidade, com a ajuda da INDECO, erguia uma escola mesmo que provisória, feita de lona e folhas de coqueiro (TEIXEIRA, depoimento, 15/04/2014 ${ }^{11}$ ). Desse modo, foram construídas 30 escolas "[...] ela dava os materiais e a comunidade construía. Outras, os proprietários de lotes, e houve mais algumas que foram a comunidade e os proprietários que construíram" (RIVA, depoimento 16/04/2014 ${ }^{12}$ ). Essas escolas rurais anexas funcionavam em um sistema diferente, contando apenas com a figura do professor de classe que também exercia a tarefa de arrumação e elaboração da merenda dos alunos.

No período de 1977 a 1980, a escola atendeu um contingente crescente de alunos, como demonstra a tabela abaixo:

Tabela 1 - Evolução do Quadro Educacional da E.E. Vitória Furlani da Riva

\begin{tabular}{lc}
\hline \multicolumn{2}{c}{ ZONAS RURAL E URBANA - 1977/1980 } \\
\hline ANO & TOTAL DE ALUNOS \\
1977 & 823 \\
1978 & 1.864 \\
1979 & 2.551 \\
1980 & 2.886 \\
\hline
\end{tabular}

Fonte: Plano de Diretrizes de Ação da Prefeitura Municipal de Alta Floresta, 1982, p. 76.

Ao analisar os dados da tabela, chama a atenção o rápido aumento da população estudantil na zona rural e urbana, passando de 823 alunos matriculados no ano de 1977, para 2.886 alunos no ano de 1980, um crescimento que demonstra, sobretudo, um aquecimento vigoroso no

11 TEIXEIRA, J. L. A. Entrevista concedida no dia 17/04/2014 em Alta Floresta-MT. Entrevistador: Clailton Lira Perin. Cuiabá: IE/UFMT 2014.

12 RIVA, V. Entrevista concedida no dia 16/04/2014 em Alta Floresta-MT. Entrevistador: Clailton Lira Perin. Cuiabá: IE/UFMT 2014. 
processo de colonização de Alta Floresta, decorrente do surgimento do garimpo, com a chamada "febre do ouro", quando recebeu pessoas de todas as regiões do Brasil, o que causou um conflito social intenso na localidade.

A documentação aponta no sentido de que a escola, através de seu ensino, festividades, e atividades sociais, tinha um papel fundamental na vida dos colonos que decidiam escolher Alta Floresta como a sua morada. Isto porque, ela desenvolvia nesses colonos uma nova identidade. Identidade que era tão forte que fazia com que os colonos se sentissem donos de cada tijolo que se levantava de uma nova construção, de cada espaço que se construísse com a força do trabalho. Fazia de Alta Floresta o seu lugar. Essa identidade era reforçada constantemente para que o colono não desistisse do projeto e abandonasse a terra. Em cada instante, os laços que os envolvia unia e fortalecia, eram destinados a formar uma nova cultura, destinada a mantê-los na terra, tendo o projeto de colonização de Alta Floresta como seu e não apenas da colonizadora e do colonizador (ROSA, PERIN, ROSA, 2003).

Enfim, a escola foi um instrumento, dentre outros, de dominação da colonizadora sobre os colonos. Onde, primeiro ela serviu para atrair o colono para o projeto, e depois fez o processo formativo de conformá-lo, através de seu currículo, às dificuldades encontradas perante a precariedades que a região apresentava.

\section{Considerações finais}

Por meio das políticas de (re) ocupação e colonização desenvolvidas a partir da década de 1970 na região sudoeste e norte de Mato Grosso, percebe-se que o uso da terra se tornou um instrumento de base para a elaboração e a execução de projetos direcionados à ocupação do território brasileiro. Por causa disso, vários colonos migraram para o estado acreditando na promessa de um futuro melhor para seus filhos.

Neste contexto, a escola foi-lhes apresentada como um instrumento de fundamental importância e foi um fator decisivo para a migração 
para Tangará da Serra e Alta Floresta, que buscavam algo melhor para si e para a sua família, pois, a representação da escola para as famílias migrantes era símbolo de futuro próspero, promissor, já que muitos pais e mães, por serem analfabetos, queriam garantir aos filhos a possibilidade de estudo e sucesso na vida.

Compreendemos que foi a luta do migrante pelo futuro promissor da família que resultou na conquista da educação escolar em Tangará da Serra, pois, consideravam que a escola possibilitaria o desenvolvimento e o sucesso para seus filhos. Nesse sentido, evidencia-se o discurso político pela educação, pela existência da escola e pela necessidade de atendimento ao movimento migratório, porém, não se percebe uma ação explícita em relação à qualidade de ensino, tendo em vista a falta de elementos que demonstrem a questão da formação dos professores, de aquisição de materiais pedagógicos, de investimentos na construção ou ampliação dos espaços escolares pelos governos municipal ou estadual.

Já em Alta Floresta houve uma preocupação com a criação da escola, mas que esta era usada principalmente para desencadear um processo formativo do colono com o projeto de colonização. Isso porque a colonizadora buscava concretizar suas estratégias de implantação e concretização do seu projeto de colonização. Mesmo com todo planejamento, as crianças que residiam aos arredores do espaço urbano, não tinham acesso à mesma estrutura física da Escola Vitória Furlani da Riva, mas compartilhavam de saberes e festividades similares, voltados para atender finalidades da colonizadora.

Percebeu-se que, nas duas localidades, diante da falta de infraestrutura adequada, os migrantes (re)significaram a realidade vivenciada através do trabalho coletivo que constituiu maneiras de fazer um novo espaço, a partir do esforço de várias famílias, resultando em superação e algumas conquistas, como a criação das primeiras instituições escolares. Nesse percurso, desafios se fizeram presentes, como também diferentes representações de escolarização da infância que foram permeando as vivências sociais na região. 
Faz-se necessário pontuar que estas cidades possuem, ainda hoje, uma forte influência da cultura sulista devido ao grande número de migrantes que constituíram estas cidades serem oriundos do Sul do país, o que, deste modo, se apresenta como um Mato Grosso "diferenciado" se comparado aos costumes e tradições da capital mato-grossense e demais cidades históricas do estado.

\section{Referências}

ABREU, S. Planejamento Governamental: a SUDECO no espaço mato-grossense. Contexto, propósito e contradições. Tese (Doutorado em Geografia) Universidade de São Paulo, São Paulo, 2001.

ALTA FLORESTA. Plano de Diretrizes de Ação. Convênio Sarem/PMAF. Alta Floresta, 1982.

BARROZO, J. C. (Org). Mato Grosso do sonho à utopia da terra. Cuiabá: EdUFMT, 2008.

BRASIL. Lei Federal No 5.173. Extingui a SPVEA e cria a SUDAM. Diário Oficial da União de 27 de Outubro 1966.

CERTEAU, M. A Invenção do Cotidiano. Artes de fazer. 10. ed. Petrópolis: Vozes, 2004.

CERTEAU, M. A Escrita da História. Trad. Maria de Lourdes Menezes, Rio de Janeiro: Forense-Universitária, 1994.

CHARTIER, R. O Mundo como Representação. Revista Estudos Avançados, São Paulo, v. 11, n. 5, p. 173-191, 1991.

GUIMARÃES NETO, R. B. A lenda do ouro verde: política de colonização no Brasil contemporâneo. Cuiabá: UNICEN, 2002.

JATENE, H. Reabertura da fronteira sob controle da colonização particular dirigida de Alta Floresta. 1983. Dissertação (Mestrado em Sociologia) - UNICAMP, Campinas, 1983. 
JOANONI NETO, V. Fronteira da Crença: Ocupação do Norte de Mato Grosso após 1970. Cuiabá: EdUFMT, 2007.

NUNES, A. Alta Floresta: Um Pioneiro por excelência. Jornal Folha da Floresta. Alta Floresta, ago., p. 09. 1989.

OLIVEIRA, C. E. Famílias e Natureza: as relações entre famílias e ambiente na colonização de Tangará da Serra - MT. Tangará da Serra: Sanches Ltda., 2004.

OLIVEIRA, C. E. Migração e Escolarização: história de instituições escolares de Tangará da Serra - Mato Grosso - Brasil (1964 -1976). 2009. Tese (Doutorado em História) - Universidade Federal de Uberlândia, Uberlândia, 2009.

PAES, A. B. A escola primária rural em Mato Grosso no Período Republicano (18891942). 2011. p. 264, Tese (Doutorado em Educação) - Universidade Estadual de São Paulo, Araraquara, 2011.

ROHDEN, J. B. A Reinvenção da Escola: História, memória e práticas educativas no período colonizatório de Sinop-MT (1973 à 1979). 2012. Dissertação (Mestrado em Educação) - Universidade Federal de Mato Grosso, Cuiabá, 2012.

ROSA, R. D.; PERIN, C. L.; ROSA, R. D. Colonizador e Colonos: na fronteira da terra o limite dos sonhos de um futuro promissor. Revista de Ciências AgroAmbientais, Alta Floresta-MT, v. 2, n. 1, p. 68-77, 2003.

SCHAEFER, J. R. As Migrações Rurais e Implicações Pastorais, um estudo das migrações campo - campo do Sul do país em direção ao norte do Mato Grosso. São Paulo: Edições Loyola, 1985.

Recebido: 03/11/2016

Received: 11/03/2016

Aprovado: 15/12/2016

Approved: 12/15/2016 
